\title{
Specific features of the relationship between creativity and inhibitory control in young adolescents
}

\author{
Elena Ivanovna Nikolaeva $^{1^{*}}$ and Evgenia Mikhailovna Belyaeva ${ }^{2}$ \\ ${ }^{1}$ Herzen State Pedagogical University, Childhood Institution, Developmental Psychology and Family \\ Pedagogics Department, Saint Petersburg, Russia \\ ${ }^{2}$ Bunin Yelets State University, Institute of Psychology and Psychophysiology, Yelets, Russia
}

\begin{abstract}
Inhibitory control develops rather late in ontogenesis since it depends on the development of the prefrontal cortex. There are contradictory data on its relationship with creativity at different stages of ontogenesis. One of the most unstudied age periods is early adolescence. It is considered an age when a child has not yet mastered the subtleties of speech expression. The purpose of the study was to reveal the connections between creativity and inhibitory control in young adolescents. Creativity is assessed with two tests: J. Gilford's test and E.P. Torrance's test. The go/go and go/no-go paradigms are used to assess inhibitory control. In the first case, subjects are presented with stimuli with a fractally organized structure. A reaction was required for each stimulus. The second case requires not responding to one of the stimuli to which one had previously developed a response. Each series consists of two identical parts. Data processing is carried out using SPSS software. The study sample consists of 158 students in grades 6-7 of which 61 are boys and 97 are girls. The result of regression analysis shows that none of the parameters of J. Guilford's test are related to the parameters of inhibitory control. We attribute this to the fact that the test is verbal and adolescents find it difficult to find original solutions in the lexical domain. Overall score and flexibility (according to E.P. Torrance's test) are related to the efficiency of inhibitory processes in the second part of the go/no-go test and to the quality of grasping the fractal structure of the sensory signal flow.
\end{abstract}

Keywords: cognitive inhibition, self-control, regression analysis.

\section{Introduction}

Currently, a common topology of human behavior involves two types: stereotypical, habitual, daily behavior and behavior focused on new tasks. Executive functions, i.e. functions controlling changes in human behavior, the functioning of which is associated with the prefrontal cortex [1] are responsible for the latter type of behavior. The prefrontal cortex appeared later than other structures in evolution, thus, it matures late in ontogenesis [2].

\footnotetext{
*Corresponding author: klemtina@yandex.ru
} 
A crucial component of executive functions is inhibitory control [3]. The functions of inhibitory control are to inhibit a certain type of behavior (self-control), to provide selective attention, and to provide cognitive inhibition (interference control). It is responsible for the inhibition of currently insignificant information and actions that have lost relevance, thus preparing the focus of attention.

Inhibitory control comprises the ability to control one's attention, behavior, thoughts, and/or emotions including the suppression of strong internal urges or external temptations. It promotes purposeful adherence to a chosen behavior that has been planned in accordance with certain requirements [1].

An analysis of the relationship between inhibitory control and creativity in adults yields extremely contradictory results [4]. They show, first of all, the varying role of inhibitory control at different stages of creative decision making: at the moment of insight [5], control seems to be minimal, while during the realization of the found solution it is, on the contrary, necessary $[6,7]$.

It is equally important to study this relationship not so much in the decision-making process but at different stages of ontogenesis. Early adolescence appears to be one of the most important ages from the point of inclusion in support. Learning to self-control, to turn off irrelevant information, is extremely useful at this age [8] since it prepares the adult version of responsible behavior. However, the degree to which it contributes to more successful creativity and implementation of creative tasks in adulthood is unknown. Moreover, this age is the least studied in terms of the relationship between creativity and inhibitory control.

All of this predetermines the purpose of the study: to investigate the possible connection between creativity and inhibitory control.

\section{Methods}

The study deploys three methods. Two methods are aimed at the assessment of creativity, namely the methods developed by J. Guilford [9] as adapted by E. Tunik [10] and E.P. Torrance [11] as adapted by A.N. Voronin [12]. The use of two separate methods is due to the type of these methods. While Torrance's method adapted into Russian is nonverbal, Guilford's test is verbal. A specific feature of younger adolescents is insufficient verbalization of internal impressions compared to subjects of a later age [8]. We hypothesize that at this age stage, there might be more connections between creativity and inhibitory control according to the parameters of Torrance's test.

Cognitive control is assessed in accordance with the go/go and go/no-go variants [13]. The test taker is offered circles of different colors on a computer screen with the instruction to press the "space" bar as quickly as possible when the stimulus appears. The method includes three series. The first series is a training series designed to evaluate the examinee's comprehension of the task. It consists of 8 circles presented at equal time intervals. In the second series, the go/go flow structure is fractal and includes two identical parts, of which the subject is not informed. It is assessed whether the subject can complete the second part of the series better than the first one which would indicate that they figured out the structure of the flow. The structure of the third series is also fractal with the flow consisting of two identical parts but the instruction is different. It is required to press "enter" when all but the red circles appear. Consequently, the subject is required to control the inhibition of the previously learned reaction. The assessed parameters include reaction time to the stimulus, the number of missed reactions, the number of erroneous actions, and whether the subject figures out that the second part of the series repeats the first one.

The study sample consists of 158 students in grades 6-7, of which 61 are boys and 97 are girls. 


\section{Results}

As all data for all methods was obtained, regression analysis was performed using SPSS ver. 21 . The objective of regression analysis was to identify relationships between the creativity parameters assessed by the two methods and the parameters of sensorimotor integration that, as it is assumed, can affect the development of creativity in young adolescents.

Neither the overall score nor the individual parameters of J. Guilford's method turned out to be related to inhibitory control.

A different situation is observed for the results obtained using E.P. Torrance's test. The independent variable "total Torrance result" influences the dependent variable "figured out the flow structure in a simple sensorimotor go/go reaction" with $\mathrm{R} 2=0.032, \beta=-0.180$, and $p=0.036$. Since we applied linear regression analysis, the higher the creativity, the more likely the subject is to discover the signal flow structure. The share of variance explained by the change in the independent variable is $3.2 \%$.

Individual parameters of E.P. Torrance's test also show a relationship with the studied factors: the more it is developed, the more effectively a child works in the second part of the simple sensorimotor reaction in the go/go paradigm (figuring out that the test consists of two identical parts) with $\mathrm{R} 2=0.049, \beta=-0.222$, and $\mathrm{p}=0.0106$.

Flexibility (Torrance's test) is the higher the lower the age of the child ( $\mathrm{R} 2=0.079, \beta=-$ 0.282 , and $\mathrm{p}=0.001$ ), and the fewer errors are made in the second part of the complex sensorimotor reaction (the adolescent discovers that the test consists of two identical parts) $\mathrm{R} 2=0.025, \beta=-0.158$, and $\mathrm{p}=0.057$.

The younger the age of the adolescent, the more thoroughly they perform the task.

Thus, we can state that almost all parameters of creativity in Torrance's test (non-verbal) are in a certain way associated with better orientation in the sensory flow.

\section{Discussion}

Our data suggest that inhibitory control is unrelated to the parameters of creativity as assessed by Guilford's verbal method. We can assume that younger adolescents are very productive in reflecting creative ideas in drawing but do not yet have enough vocabulary to translate them into words [14]. Inhibitory control was assessed using simple and complex sensorimotor responses in go/go and go/no-go paradigms. The measured parameters were reaction time to the stimulus, the number of errors (pressing the forbidden signal), and the number of omissions (no response to the presented signal). Our results indicate that it not so much inhibitory reactions that correlate with creativity as the intuitive ability to predict the structure of the fractally organized signal flow. The absence of any connection between creativity and the level of inhibitory control can be explained by the fact that inhibitory control in young adolescents is still in the stage of formation due to the long period of maturation of the prefrontal cortex $[15,16]$ while orientation in the flow of signals in space is determined by structures of the right brain hemisphere that is already developed sufficiently at this age.

\section{Conclusion}

The results of J. Gilford's verbal test are not related to inhibitory control, whereas the creativity parameters assessed with a nonverbal Russified adaptation of E.P. Torrance's test are linked to certain parameters of sensorimotor reactions in the go/go and go/no-go paradigms. Test takers with higher creativity scores are better at navigating the structure of the sensory flow. 
In younger adolescents, inhibitory control is still in the stage of formation, therefore, it is not associated with the general creativity indicator but is connected to the scale of flexibility: the higher the creativity of a younger adolescent, the higher their flexibility in the test.

\section{References}

1. E.I. Nikolaeva, E.G. Vergunov, Teoreticheskaia i eksperimentalnaia psikhologiia, 10(2), 62-81 (2017)

2. A. Fiske, K. Holmbo, Developmental Review, 52, 42-62 (2019). https://doi.org/10.1016/j.dr.2019.100866.

3. A. Bari, T.W. Robbins, Progress in Neurobiology, 108, 44-79 (2018). https://doi.org/10.1016/j.pneurobio.2013.06.005.

4. M. Benedek, E. Jauk, Creativity and Cognitive Control, in J. C. Kaufman, R. J. Sternberg (Eds.), The Cambridge Handbook of Creativity (Cambridge academy press, New York, 2019). https://doi.org/10.1017/9781316979839

5. R. E. Beaty, P.J. Silvia, E.C. Nusbaum, E. Jauk, M. Benedek, Memory and Cognition, 42, 1186-1195 (2014). https://doi.org/10.3758/s13421-014-0428-8

6. B.A. Hennessey, T.M. Amabile, Annu Rev Psychol 61, 569-598 (2010). https://doi.org/10.1146/annurev.psych.093008.100416

7. L. Cheng, W. Hu, X. Jia, M.A. Runco, Psychology of Aesthetics, Creativity, and the Arts, 10, 32-41 (2016).

8. B. Luna, S.Marek, B. Larsen, et al., Annual Review of Neuroscience, 38, 151-170 (2015). https://doi.org/10.1146/annurev-neuro-071714-034054.

9. J.P. Guilford, Creativity: a quarter century of progress, in I. Taylor, J. Getzels (Eds.), Perspectives in creativity, 37-59 (Aldine, Chicago, 1975)

10. E. Tunik, Psikhodiagnostika tvorcheskogo myshleniia. Kreativnye testy [Psychodiagnostics of creative thinking. Creative tests.] (Didaktika plius, Moscow, 2002)

11. E.P. Torrance, Creativity as manifested in testing, in R. J. Sternberg (Ed.), The nature of creativity, 43-75 (Cambridge University Press, New York, 1988)

12. A.N. Voronin, Metody psikhologicheskoi diagnostiki. Vypusk 2 [Psychodiagnostic methods. Issue 2] (Institute of Psychology of the Russian Academy of Sciences, Moscow, 1994)

13. E.G. Vergunov, E.I. Nikolaeva, N.V. Balioz, S.G. Krivoschekov, Human Physiology, 44(3), 12 - 21 (2018). https://doi.org/10.1134/S0362119718030143.

14. E.C. Burns, Journal of Adolescence, 84, 180-189 (2020). https://doi.org/10.1016/j.adolescence.2020.09.005

15. K. Rubia, A.B. Smith, E. Taylor, M. Brammer, Human Brain Mapping, 28(11), $1163-$ 1177 (2007). https://doi.org/10.1002/hbm.20347.

16. A. Miyake, N.P. Friedman. Current Directions in Psychological Science, 21(1), 8-14 (2014). https://doi.org/10.1177/0963721411429458. 